\title{
Editorial
}

\section{Feminist Technoscience: Intimacy, Embodiment and Abjection in Science Studies}

In this special issue, we showcase some cutting edge feminist engagements with technoscience. Recent years have seen an increasing convergence of social/cultural studies of technology with the interests of feminist theory. Current writing in feminist STS now, more than ever before, looks outwards towards a wide range of feminist writings and influences, thus continuing to pose challenges both epistemologically and methodologically, to the wider STS field. While the specific relationships between women, science, and technology remain an important focus in feminist STS, and are explored here in various forms, this special issue is more concerned with showcasing insights into technoscience provided by feminist theory's engagements with ideas of nature, the body, scientific productivity, and such undertheorized areas as affect, intimacy, and perception. The contributions to this special issue are drawn from a UK Economic and Social Research Councilfunded seminar series initiated by the editors, and held throughout 2004, as a first UK attempt to bring together feminist scholars from Europe, North America and Australia whose work does not look narrowly at the "impact" of one particular technology, but rather at the wider issues at stake in technological cultures and social change. Feminist STS provides a uniquely interdisciplinary site for such engagements. It can consider not only the social relations of science and technology as they are framed sociologically, but also the ontological and experiential dimensions of embodiment and its complex relation to nature, the object of technoscience.

So, on the one hand, Celia Roberts in her piece for this volume, "What Can I Do to Help Myself", is fully engaged with the broad socio-economic transformations associated with neo-liberalism, with its complex implications for relationships between gendered patients, medical practitioners and the production and interpretation of clinical evidence in an age of ever-devolving risk. She accurately pinpoints the gender asymmetries in the neo-liberal state's demand for responsibilised, healthy subjects. While the assumed subject of this demand is the genderless "autonomous individual" who cares for himself alone, it has a disproportionate impact on women, who so often care for others.

On the other, she and the other contributors to this volume are fully alert to 
the implications of what can at first appear to be pre-critical and apolitical arenas of experience - affect, pleasure, sexuality, intimacy - and the extent to which such apparently ephemeral experience is mediated by specific forms of scientific and technological practice. This mediation is most evident in the work engaged with biomedicine and patient experience, represented here by Karen Throsby and Celia Roberts. In their essays, they investigate the ways in which women come to grips with the most intimate and confronting arenas of feminine identity - ageing and menopause (Roberts) and maternity, fertility and childlessness (Throsby) - via extensive and often painful engagement with the technologies of hormone replacement therapy and IVF. In each case, the availability of these highly gendered technologies produces identity dilemmas around new techno-social norms; what constitutes socially and clinically acceptable forms of ageing? What constitutes a fertile body and at what point does childlessness become a socially acceptable state? In their accounts we can see that new arenas of subjective life and identity negotiation are opened up by technoscientific innovation. Throsby's essay suggests that, contrary to the assumptions of some STS work, these normative and affective dilemmas are most sharply experienced when innovative treatment fails, and patients are left without an explanation for their exclusion from technoscientific redemption. These situations, she argues, have just as strong a claim on the analytic attention of STS scholars as the more privileged novel objects - ex vivo embryos, genetically modified organisms, transplant patients - that tend to populate the pages of STS journals.

Throsby's article deals with what is cast out of the technoscientific self-image - in her case the failures of technology to govern biology, and the messy experiential consequences of this. Natasha Myers' piece on the performativity of protein folding (Animating Mechanism: Animations and the Propagation of Affect in the Lively Arts of Protein Modelling) makes a similar move in identifying the excluded forms of sense making involved in the production of scientific knowledge. Through ethnographic work in a protein crystallography lab, Myers documents the extent to which the apparently abstract, analytic processes of scientific knowledge production depend on a wide range of pre- or nonscientific ways of knowing. Her scientists demonstrate, to use Evelyn Fox Keller's phrase, their "feeling for the organism", through their embodied intuitions about the biology of protein folding, and their sense of what works, which precede any attempts at properly scientific demonstration. Myers is alert to the implication of apparently unscientific craft in more properly scientific fields of research. Her crystallographers draw eclectically on performance, art, cinema and animation to make their models and give full, spatial consideration to the ways proteins unfold in biological space. They enact a complex, imaginative, intimate relationship with the proteins that they study, rather than the drained and removed relationship suggested by the aesthetics of genetic code. Here Myers and Throsby are offering thoughts that are fundamental to feminist insight. They reconsider and revalue the abject categories of science, the aspects of its own practice and its consequences that 
tend to be expunged from its self account. They ask what the devalued categories of scientific practice can tell us about what science does and how it works, and what a more full account of science might look like.

Perhaps a more expansive account of technoscientific practice would look more seriously (playfully? lovingly?) at the notion of pleasure. Myers begins with a fieldwork anecdote of being interrupted in her note taking by her interlocutor who wanted to physically demonstrate the strength with which molecules in a protein are joined. They grasp hands. This partly playful gesture points to the pleasures of the crystallographers in relation to their performances. The theorization of pleasure in relation to cars and masculinity is the starting point for Catharina Landström's paper "A Gendered Economy of Pleasure: Representations of Cars and $\mathrm{Hu}$ mans in Motoring Magazines”. Motoring magazines continually remake associations between men, masculinity and cars. In this world of "smooth" and "warm" carbon fibre, of "slow rumble" and "muscular shape", the magazines foreground sensory experiences and an imagined homosocial community is sustained. Women and femininity are excluded on the grounds of their perceived polluting rationality: "[a car] which actually does something”. Yet Landström is not content with a constructivist approach, and insists on a post-humanist approach to subjectivity. Thus pleasure becomes an aspect of the process of interpellating humans into assemblages. Her article is a provocation to feminist STS: could we subvert the gendered economy of pleasure by bringing to the foreground women's actual relationship with cars; how can feminist STS continue to grapple with the issues of sexual and gender difference, and what kinds of feminist theories will aid us in this endeavour?

One of the risks of a journal collection such as this is that it highlights the most normative practice of feminist STS: writing refereed journal articles. Yet this is not all there is. During our seminar series we elicited a set of manifestos for the future of feminist STS from scholars who are not published here. These included confessions, polemics, fears and desires, often in the form of spoken performance pieces that would be unsuited, and indeed fundamentally betrayed, by publication in a refereed journal. Even the photographic documentation of speakers in full flow around a seminar room would not do justice to the subtlety of the interventions. Yet by writing fiction Sarah Kember is attempting to perform scientific knowledge differently, while drawing on a feminist theoretical heritage. Meanwhile Ann Kalowski-Naylor, in a poetic gesture, asked seminar participants to send Valentine's cards to feminist STS (care of her address)! Omitting to mention the presence of such STS practice reinforces the idea of a single mode of academic production which STS fundamentally sets out to question. If the crystallographers are shaking hands and dancing their models of technoscience, surely we could experiment a little?

Catherine Waldby, Nina Wakeford and Nicola Green Guest Editors 